\title{
0 eterno retorno do mesmo e a subversão da noção de fatalismo
}

The eternal recurrence and the subversion of the notion of fatalism

\author{
João Evangelista Tude de Melo Neto \\ Universidade Católica de Pernambuco
}

\section{RESUMO}

Tradicionalmente, 'fatalismo' é compreendido como uma doutrina que ensina a rigidez de um fado que anula o poder das ações humanas. Essa acepção de fatalismo não é, contudo, corroborada por Nietzsche. $\mathrm{O}$ autor, entretanto, não abandona o termo e passa a compreendê-lo num sentido subvertido. Levando isso em conta, os objetivos de nosso trabalho consistem em: I) examinar de que forma Nietzsche compreende o termo 'fatalismo' em alguns momentos de sua obra; 2) tentar mostrar que as acepçôes de fatalismo nesses momentos possuem correspondência conceitual; 3) tentar entender a noção de fatalismo à luz da cosmologia nietzschiana.

\section{PALAVRAS-CHAVE}

Fatalismo; Tempo; Eterno retorno do mesmo; Cosmologia; Transvaloração.

\begin{abstract}
Traditionally, 'fatalism' is understood as a doctrine that teaches the rigidity of a fate that nullifies the power of human actions. This sense of fatalism is not, however, corroborated by Nietzsche. The author, nevertheless, does not abandon the term and understands it in a subverted sense. Considering this, the objectives of our work are: I) to examine how Nietzsche understands the term 'fatalism' at some moments of hisworks; 2) try to show that the meanings of fatalism at these moments have a conceptual correspondence; 3 ) try to understand the notion of fatalism from Nietzschean cosmology.
\end{abstract}

\section{KEY WORDS}

Fatalism; Time; Eternal recurrence; Cosmology; Revaluation of values. 


\section{Introduzindo a questão}

Uma maneira corrente de se compreender o fatalismo é pensá-lo como a doutrina que ensina a necessidade inevitável do cumprimento do fado (ou destino). Isto é, o fatalismo consistiria na ideia segundo a qual todos os acontecimentos já estão, de antemão, irremediavelmente fixados e que o destino será forçosamente realizado. Nesses termos, a ação humana, apesar de ser entendida como uma espécie de força de oposição ao destino, sempre seria vencida e anulada por este. Enfim, conforme essa compreensão tradicional de fatalismo, o homem seria impotente frente ao fado, uma vez que tudo já estaria determinado independentemente de qualquer ação. ${ }^{\mathrm{I}}$

Essa noção de fatalismo não é, todavia, corroborada por Nietzsche. Ao contrário, é como alvo de críticas que ela, geralmente, aparece em seus textos. Seus escritos, na maioria das vezes, apresentam outra versão para o conceito. Isso porque a argumentação desenvolvida pelo filósofo defende, de forma recorrente, que a dualidade "fado e vontade" não consistiria numa dicotomia, mas numa oposição em que os polos são necessariamente complementares e interdependentes. ${ }^{2}$ Tendo em mente que Nietzsche subverte o sentido usual de 'fatalismo', sem, contudo, abandonar o termo, iremos examinar de que forma o filósofo vai compreendê-lo em alguns momentos de sua obra. ${ }^{3}$ Por intermédio desse procedimento, almejamos mostrar que, a despeito dos diferentes contextos nos quais o termo aparece, as recorrências de 'fatalismo' guardam, em diferentes momentos dos escritos nietzschianos, uma unidade conceitual. Por fim, tentaremos demonstrar que, com a versão cosmológica da doutrina do eterno retorno do mesmo, o filósofo tentou levar a sua noção de fatalismo a uma fase de acabamento e, ao mesmo tempo, utilizá-la como uma espécie de ferramenta conceitual a favor do seu projeto de transvaloração dos valores.

I Fatalismo é um termo de sentido filosófico muito ambíguo o qual, geralmente, expressa que o 'destino' consiste numa força exterior que determina, previamente, o transcorrer das vidas humanas. Vejamos o que Lalande tem a dizer sobre fatalismo e destino. Sobre o fatalismo: "Doutrina segundo a qual a vontade e a inteligência humanas são impotentes para dirigir o curso dos acontecimentos, de modo que o destino de cada um está fixado antecipadamente, seja o que for que se faça” (Lalande, 1999, p. 286). Sobre Destino: "Propriamente, potência pela qual certos acontecimentos seriam fixados antecipadamente independentemente do que pudesse acontecer, e do que os seres dotados de inteligência de vontade pudessem fazer com vista para evitá-los" (Ibid., p. 242). Segundo Lalande, são termos mais ligados ao poético do que, propriamente, à filosofia (Ibid., p. 243).

2 Fornazari já havia chamado atenção a respeito dessa especificidade da compreensão nietzschiana acerca do fatalismo (cf. Fornazari, 2004, p. 47).

3 Levando em conta a tradicional divisão da obra de Nietzsche, elencamos passagens desses três momentos. 


\section{0 fatalismo nietzschiano: de Pforta à noção de ego fatum}

Já em Fado e História - ensaio redigido em I862, época em que o filósofo tinha apenas 17 anos - , um esboço da versão nietzschiana de fatalismo já pode ser verificada. ${ }^{4}$ No texto em questão, o jovem pensador reflete acerca da oposição entre "livre vontade" " "fado" e defende que cada uma dessas duas noções só pode ser concebida quando ambas são colocadas, frente a frente, numa mútua relação de contrariedade conceitual. ' Ou seja, seria justamente a oposição conceitual entre elas que daria as características definidoras de cada uma: "livre vontade sem fado é tão pouco concebível como o espírito sem real, bem sem mal. Pois só a oposição cria o atributo". ${ }^{6}$ Parece, portanto, que, por meio desse raciocínio, Nietzsche tenta provar a interdependência ontológica da relação entre as noções. Ora, sugerimos que não nos preocupemos em averiguar a validade da argumentação e nem a verdade da conclusão do jovem estudante de Pforta. Isso porque nosso objetivo não é verificar a legitimidade ou a correção filosófica de Fado e História, mas dar relevo à preocupação de Nietzsche em resolver o problema determinação x liberdade por meio da superação da própria dicotomia em questão. Em suma, o que podemos extrair de Fado e História é que o pensador, ao tentar demonstrar que as noções de 'determinação' e 'liberdade' estariam logicamente imbricadas, parece almejar nos provar que eles não seriam autoexcludentes em termos ontológicos.

Fado e História ainda nos fornece outro elemento teórico que ajuda a corroborar nossa hipótese. Nesse escrito, Nietzsche também vai entender os dois "conceitos" - vontade livre e fado - a partir de uma espécie de cosmovisão, segundo a qual o Universo consistiria num vir-a-ser cíclico que se desenrola em círculos concêntricos os quais parecem segmentar o cosmo em níveis de "realidades" com distinções qualitativas. Esses círculos também seriam de dimensōes variadas, sendo que os maiores compreenderiam os menores. Ou seja, os círculos

4 Fado e História trata-se de um pequeno ensaio filosófico apresentado, por Nietzsche, à sociedade lítero-musical, a Germânia. Fundada em I862, durante a época dos estudos em Pforta, a Germânia era integrada por Nietzsche e os amigos Carl von Gersdorff e Paul Deussen.

5 Nesse texto, Nietzsche recorre a uma espécie de "lógica” heraclítica para guiar sua argumentação. Não podemos, contudo, precisar se já existia realmente uma influência de Heráclito no pensamento do jovem Nietzsche nos tempos de Pforta. No entanto, se levarmos em conta que, já em I858 - no primeiro ano de estudos em Pforta - o filósofo teve aulas de grego a partir do Fédon de Platão, podemos talvez concluir que, pelo menos de forma indireta, ele teve contato com a filosofia de Heráclito. Isso porque Platão - no Fédon 70 e, $7 \mathrm{I}$ a-b-c — realiza uma discussão sobre a noção heraclítica da luta dos contrários (cf. Platão, 2002, p. 268 e 269). Lembremos que Fado e História é de I862, ou seja, de um período posterior a essas aulas.

6 Fado e História, 2005, p. I66. Tradução conforme Paulo Cesar de Sousa. A partir de agora indicado como PCS. 
menores estariam mais aproximados do centro e os maiores mais afastados. Os círculos mais amplos e mais periféricos consistiriam no movimento da "história universal", enquanto que os menores e mais centrais estariam relacionados com a "história dos povos, da sociedade e da humanidade". ${ }^{7}$ Nesse "processo" cíclico, tanto o vir-a-ser da natureza quanto o da história — este inserido naquele — se moveriam sem uma finalidade pré-estabelecida, isto é, sem télos. Examinemos o que diz o filósofo:

Jamais tem fim, esse devir? Quais são as molas desse grande mecanismo? Estão ocultas, mas são as mesmas desse grande relógio que chamamos história. $\mathrm{O}$ mostrador são os acontecimentos. A cada hora avança o ponteiro, para recomeçar sua ronda após as doze; começa um novo período do mundo... ${ }^{8}$ Tudo se move em círculos imensos, sempre mais amplos; o homem é um dos círculos mais interiores. Querendo medir as oscilações daqueles exteriores, ele terá de, a partir de si e dos círculos mais próximos, abstrair aqueles mais abrangentes. Os mais próximos são a história dos povos, da sociedade e da humanidade.

Conforme essa cosmovisão, o homem estaria, portanto, inserido num dos menores círculos que constituem o Universo. No interior desse pequeno círculo, um dos mais próximos do centro, é onde seria possível, na ótica do filósofo, conceber-se uma "vontade livre" ou "vontade individual". Essa disposição "geográfica" faria com que essa "vontade individual" estivesse, portanto, restrita a um dos menores círculos desse esquema concêntrico. À medida que houvesse o afastamento do centro e o consequente aumento dos círculos, estaríamos nos aproximando gradativamente de um fado social e posteriormente de um fado físico, contra os quais a "vontade individual" teria de se confrontar:

$\mathrm{Na}$ medida em que o homem é arrastado nos círculos da história universal, surge essa luta da vontade individual com a vontade geral; aqui se insinua este problema infinitamente importante, a questão do direito do indivíduo ao povo, do povo à humanidade, da humanidade ao mundo; aqui se acha também a relação fundamental entre fado e história. ${ }^{10}$

Se levarmos em conta o raciocínio desenvolvido no ensaio nietzschiano, teremos de concluir que o círculo no qual se encontra a "vontade individual"

7 Ibid., p. 165.

8 É digno de nota que o trecho citado apresenta algumas noções que, posteriormente, estariam presentes na doutrina do eterno retorno. Por exemplo: a visáo cíclica de tempo e a negação de uma teleologia do vir-a-ser. Além disso, o texto traz, até mesmo, a metáfora das "doze horas", a qual será utilizada para aludir ao recomeço de ciclos cósmicos.

9 Fado e História, 2005, tradução de PCs, p. 165.

Io Ibid., p. I65. 
estaria no interior de outros grandes círculos de determinações sociais e físicas. Nesse sentido, parece que o jovem Nietzsche tenta mostrar que a "vontade individual" teria de ser compreendida como estando sempre atrelada ao âmbito fatalista do Cosmo. Logo, essa "vontade individual" — apesar de concebível na hipótese cosmológica em questão - consistiria numa parcela ínfima do grande vir-a-ser, o qual se desenrola de forma majoritariamente determinista. Em suma, essa "vontade individual" é concebida, aqui, como estando sempre circundada por um "fado" cultural, biológico e físico:

Uma conformação fatalista do crânio e da coluna vertebral, a condição da natureza de seus pais, o cotidiano das suas relações, o ordinário de seu ambiente, mesmo o monocorde de seu lugar natal. Fomos influenciados sem carregar conosco a força suficiente para contrariar estas influências, sem saber sequer que estamos sendo influenciados. ${ }^{\text {II }}$

Em outros termos, cada homem agiria "influenciado" inconscientemente por determinaçôes que escapam a sua escolha, uma vez que a ação humana se daria a partir de - e sobre - uma imensa dimensão fatalista da qual a própria ação seria parte integrante. Portanto, concebendo o homem como um ente possuidor de uma vontade livre, mas que, ao mesmo tempo, estaria inserido em círculos de determinações sociais e fisiológicas, o jovem Nietzsche vai tentar afastar a unilateralidade exclusiva dos polos 'vontade' e 'fado'. Aqui, o homem nem é entendido como detentor de uma livre vontade absoluta, nem como um ente completamente determinado pelo fado. É nesse sentido que ele conclui o texto da seguinte forma: a "livre vontade absoluta, sem fado, transformaria o homem em Deus; o princípio fatalista em um autômato". ${ }^{22}$ Desse modo, para o estudante de Pforta, o ser humano não poderia ser compreendido como um "Eu autônomo" separado do vir-a-ser, nem como um simples joguete das determinações do mundo, pois cada homem estaria integrado a todos os outros círculos que constituem o cosmo. Enfim, a despeito de Fado e História apresentar a hipótese de um jovem pensador que parece ainda não desenvolver suas argumentações de forma totalmente satisfatória, entendemos, contudo, que podemos enxergar, nesse escrito, o germe de um projeto filosófico que visa conceber o ser humano como parte constitutiva e necessária do mundo.

Em O Andarilho e sua Sombra (I880), a despeito de elaborar uma formulação argumentativa completamente diferente, Nietzsche parece manter, em conteúdo, uma concepção acerca do fado semelhante a que expressou em Fado e História. Isso porque, no texto de I880, o filosofo também tenta fugir da mera oposição

\footnotetext{
II Ibid., p. I66.

I2 Ibid., p. I68.
} 
excludente entre o fado e as ações humanas. Na seção 6I, intitulada de Fatalismo turco, Nietzsche defende que a separabilidade entre o fado e a ação humana é algo inconcebível, uma vez que esta seria parcela necessária à efetivação daquele. Dito de outra forma, a ação do homem não estaria contraposta de forma excludente ao fado, mas consistiria, no entanto, na condição para efetivação do próprio fado. Examinemos o trecho:

Fatalismo turco. - O fatalismo turco tem o defeito fundamental de contrapor o homem e o fado como duas coisas separadas: o homem, diz ele, pode contrariar o fado, tentar frustrá-lo, mas este sempre termina vitorioso; por isso o mais sensato seria resignar-se ou viver a seu bel-prazer. $\mathrm{Na}$ verdade, cada ser humano é ele próprio uma porção de fado; quando ele pensa contrariar o fado da maneira mencionada, justamente nisso se realiza também o fado; a luta é uma ilusão, mas igualmente a resignação ao fado; todas essas ilusões se acham incluídas no fado. - $\mathrm{O}$ medo que a maioria das pessoas tem da teoria da não-liberdade da vontade é o medo do fatalismo turco: elas acham que o ser humano fica débil, resignado e de mãos atadas ante o futuro, porque não consegue mudá-lo: ou então que ele afrouxará inteiramente a rédea ao seu capricho, porque tampouco esse poderá piorar o que já foi determinado. As tolices do homem são uma parcela de fado, tanto quanto suas sabedorias: também aquele medo da crença no fado é fado. Você mesmo, pobre amedrontado, é a incoercível Moira que reina até sobre os deuses, para o que der e vier; você é a bênção ou maldição, e, de todo modo, o grilhão em que jaz atado o que é mais forte; em você está de antemão determinado o porvir do mundo humano, de nada lhe serve ter pavor de si mesmo. ${ }^{\text {I3 }}$

Colocando em xeque essa doutrina que ele denomina de "fatalismo turco", o filósofo afirma que o "fatalismo turco tem o defeito fundamental de contrapor o homem e o fado como duas coisas separadas. [...] Na verdade, cada ser humano é ele próprio uma porção de fado; quando ele pensa contrariar o fado da maneira mencionada, justamente nisso se realiza também o fado" ${ }^{14}$ Ora, se aderirmos à hipótese sugerida por Nietzsche, teríamos, então, de concluir que o futuro não estaria determinado, de antemão, por algo apartado do homem. Ao contrário, a posteridade dependeria do próprio homem, uma vez que este seria parcela necessária ao fado. É pensando nessa direção que o filósofo então afirma: você "mesmo, pobre amedrontado, é a incoercível moira que reina sobre os deuses, [...] em você está de antemão determinado o porvir do mundo humano, de nada lhe serve ter pavor de si mesmo". ${ }^{\text {Is }}$ Nesse contexto, o fatalismo não poderia, por

I3 O Andarilho e sua Sombra $\$$ 6I, 2008, KSA 2.580, tradução de PCS.

I4 Ibid.

Is Ibid. 
conseguinte, ser entendido a partir de uma espécie de télos estabelecido por uma força maior e exterior ao transcorrer dos acontecimentos, visto que não haveria uma prévia determinação conforme a qual o homem não fosse, ele também, uma força atuante no cumprimento do destino. Aqui, o fado não é um alvo a se atingir, mas a ligação necessária de todos os momentos do próprio vir-a-ser. Defendendo essa posição, Nietzsche deixa claro que, no seu entender, "contrariar" ou "resignar-se" ao fado seriam, ambas, atitudes fatalistas, pois, se "a luta é uma ilusão", a resignação a esse fado também o seria. ${ }^{16}$ Logo, não haveria efetivamente uma oposição entre fado e ação, já que qualquer ação humana — "contrária" ou a "favor" do fado - constituir-se-ia como fado.

Em um fragmento póstumo da primavera de $1884^{\mathrm{I7}}$, Nietzsche desenvolve um raciocínio que vai na mesma direção de $O$ Andarilho e sua Sombra: "cada ação humana tem influência ilimitadamente grande no todo vindouro" e, por isso, a "mesma veneração que ele, olhando para trás, dedica ao destino inteiro, tem de dedicar também a si mesmo. Ego fatum". ${ }^{18}$ Ora, com essas sentenças e por meio da expressão ego fatum, o filósofo parece corroborar, cerca de cinco anos após a publicação de $O$ Andarilho e sua Sombra, sua posição acerca da impossibilidade de separação entre o as 'açóes de cada homem' e o 'fado'. Em outras palavras, no contexto conceitual do ego fatum, as 'açôes de cada um' e o 'fado' estariam imbricados de tal forma que ficaria impossível indicar a primazia de um sobre o outro. ${ }^{19}$ Também aqui, 'ação' e 'fado' não podem ser concebidos por meio daquela velha dicotomia em que o 'fado' determina a 'ação'. ${ }^{20}$ Ao contrário, a 'ação humana' possui "influência ilimitadamente grande no todo vindouro" e, por isso, também "determina” a maneira de ser desse mesmo 'fado'.

No nosso entender, o fragmento póstumo de I884 e a noção de ego fatum estão em plena consonância com algumas passagens de Crepúsculo dos Ídolos, obra da fase final do pensamento nietzschiano. Na seção seis do capítulo "Moral como antinatureza", Nietzsche considera que "o indivíduo [é], de cima a baixo,

I6 Cf. Ibid.

I7 Cf. Fragmento póstumo 25 [I58] da primavera de I884, KSA II.55.

I8 Fragmento póstumo 25 [I58] da primavera de I884, KSA II.55.

I9 Marton defende que a noção de ego fatum coloca em xeque "a oposição entre ego e fatum" e, por essa razão, poderia levar-nos a entender "que o ser humano partilha o destino de todas as coisas" (Marton, 200I, p. II7). Ver também: Marton, 20IO, p. I55. Em outras palavras, um homem que sentisse seu ego como sendo parte necessária do cosmos poderia afirmar o eterno retorno de todas as coisas: "quem percebe que seu próprio ser está envolvido no cosmos" poderia "afirmar tudo o que foi e será" (Ibid., p. I55).

20 A esse respeito, conferir a posição de Haar, o fatum "não é de maneira nenhuma um encadeamento 'objetivo', posto fora de mim, de todos os acontecimentos do mundo [...] concebidos como inevitáveis e determinados de antemão” (Haar, I993, p. I64). 
uma parcela de fatum [fado, destino] [...], uma necessidade [...] para tudo o que virá e será" ${ }^{21}$ No mesmo sentido, também vai a seção oito de "Os quatro grandes erros", na qual ele afirma que a "fatalidade do seu ser [do homem] não pode ser destrinchada da fatalidade de tudo o que foi e será. [...] Cada um é necessário, é um pedaço do destino, pertence ao todo, está no todo [...]" ${ }^{22}$ Como é possível conferir, esses trechos corroboram ainda mais a tese de que a noção nietzschiana de fatalismo permanece praticamente inalterada ao longo da obra do autor de Zaratustra. Todavia, a partir desse ponto, se faz necessário explicar o que, de fato, justifica teoricamente o conceito de 'ego fatum'. Isto é, por que "cada um é necessário e está no todo"? Qual é a razão que faz com que "o indivíduo [seja] uma necessidade para o que foi e será"?

\section{0 fatalismo e o âmbito cosmológico do terno retorno do mesmo}

Sustentamos a tese de que a noção nietzschiana de fatalismo pode ser melhor compreendida à luz do âmbito cosmológico do pensamento do filósofo, sobretudo, se levarmos em conta as doutrinas da vontade de potência e do eterno retorno. Vejamos. Na ótica de Nietzsche, as ações humanas não poderiam ser entendidas como decisões tomadas a partir de uma espécie de puro 'eu' substancial. Isso porque os seres humanos consistiriam numa unidade múltipla de vontades de potência. Ou seja, cada homem, em cada instante, seria a resultante temporária de configurações hierárquicas de forças que se relacionam constantemente com outras composiçõos hierárquicas de forças. Por isso, suas ações estariam atreladas indissoluvelmente a forças atuantes nele e contra ele. Nesse sentido, a noção de vontade de potência vai oferecer outra possibilidade de se conceber a relação entre homem e mundo. Sendo um composto de forças o qual se opõe a outras forças cósmicas, o homem não pode ser, portanto, pensado como um ente substancial que possui o poder da deliberação como uma espécie de atributo essencial do seu modo de ser. Tampouco, o ser humano poderia ser entendido como um joguete dessas forças, pois ele também seria essas forças e, por conseguinte, tomaria parte na disputa que configura todas as coisas do Universo. Em resumo, se por um lado, o filósofo afasta de sua cosmologia uma noção de determinismo a qual iria compreender o transcorrer do destino como algo independente das açôes humanas, por outro lado, ele também não vai cair no voluntarismo à maneira do livre-arbítrio.

Sabemos que, em seus fragmentos póstumos, Nietzsche desenvolve uma espécie de cosmologia na qual o Universo é compreendido como um vir-a-ser

2I Crepúsculo dos Ídolos, "Moral como antinatureza", $\$$ 6, KSA 6.87, tradução de PCS.

22 Ibid. "Os quatro grandes erros", $\$ 8$, KSA 6.96, tradução de PCS. 
de ciclos cósmicos que se repetem eternamente. ${ }^{23}$ Nesses ciclos, todas as configuraçôes cósmicas de cada ciclo deveriam, necessariamente, retornar de forma identicamente encadeada. Assim sendo, cada estado do cosmo se repetiria e condicionaria, obrigatoriamente, o retorno sequencial de todos os mesmos estados de cada ciclo cósmico. Nesses termos, qualquer estado presente, além de condicionar todos os estados "passados" e "futuros", condicionaria a si mesmo. Sem alvo a atingir, esse vir-a-ser cíclico se repetiria numa total ausência de télos. Ora, se levarmos em consideração esse ponto de vista cosmológico, então teríamos de concluir que cada homem, enquanto parte integrante e necessária do cosmo, também retornaria infinitas vezes nos eternos ciclos de retorno.

$\mathrm{Na}$ verdade, essa cosmologia coloca em xeque as principais noções que orientam a cosmovisão ocidental - sobretudo a cosmovisão cristã e a platônica —, uma vez que as concepções de 'criação divina', 'fim dos tempos', 'dualidade de mundos', 'finalismo para o vir-a-ser', 'vida eterna no além' e 'Deus providente' seriam substituídas pela doutrina da eterna repetição não teleológica das mesmas configuraçôes cósmicas. No lugar da cosmovisão linear que vige no Ocidente, colocar-se-ia, portanto, uma concepção circular que compreenderia o movimento cósmico como sendo constituído por grandes círculos de retorno. Em substituição à noção da vontade providente de Deus, teríamos uma concepção que professa a total ausência de télos - conforme a doutrina, o cosmo se transformaria eternamente, sem propósito algum, em repetidos períodos circulares de tempo. Nenhuma inteligência, transcendente ou imanente, estaria regendo o movimento da história ou da natureza, já que este seria resultado do combate incessante das forças. Enfim, o ensinamento do eterno retorno do mesmo colocou em xeque, ora os dualismos do cristianismo - "mundo terreno versus mundo do além", "vida terrena versus vida eterna” —, ora as dicotomias da metafísica platônica — "transitório versus perene", "mutável versus permanente", "sensível versus inteligível”, "ideal versus material".

No nosso entender, é necessário ressaltarmos, no entanto, outros dois pares de dualidades que também são questionados pela doutrina. São eles: "causa e efeito" e "determinação versus liberdade". ${ }^{24}$ Examinemos o primeiro. Ora, se pensarmos

23 Podemos relembrar a argumentação do próprio Nietzsche: "Num tempo infinito, obter-se-ia qualquer combinação possível num momento ou noutro; melhor ainda: ela seria obtida um número infinito de vezes. E assim como, entre cada 'combinação' e seu 'retorno' seguinte, todas as combinações possíveis deveriam decorrer, e cada uma dessas combinaçôes determinaria toda a sequência das combinações na mesma série, e com isso ficaria provada a existência de um ciclo de séries exatamente idênticas [...]." (Fragmento póstumo I4 [I88] da primavera de I888, KSA I3.376).

24 Acerca dessa questão, conferir também a posição de André Itaparica: Itaparica, 20I6, pp. I37-I39. Verificar também o verbete "livre-arbítrio" no Dicionário Nietzsche do GEN: Itaparica, 20I6, pp. 288-290. 
a partir do ensinamento circular do eterno retorno, teremos de dissolver essa dualidade tão cara à ciência e à metafísica, visto que, num tempo eterno e circular, torna-se impossível conceber a anterioridade da 'causa' em relação à posterioridade do 'efeito'. De fato, se há apenas um encadeamento circular, nenhum momento do cosmo pode ser considerado, num sentido estrito, antecedente ou posterior a qualquer outro momento. Nesses termos, o momento considerado como efeito seria tão "causa" de sua causa, quanto o inverso. Logo, esse par de conceitos perderia seu sentido e daria lugar a uma noção de necessidade circular, segundo a qual cada configuração cósmica "determinaria" todas as outras e, ao mesmo tempo, seria por elas "determinada”. Em suma, quando não há anterioridade temporal de nenhuma configuração ou elemento do cosmo, fica interditada a noção de causalidade. Aqui, levamos em conta, sobretudo, a noção de causalidade eficiente. Contudo, se pensarmos o conceito de causalidade final a partir do registro do eterno retorno, iremos verificar que ele também perde um pouco do seu sentido. Visto que, no movimento circular do cosmo, tudo se repete em cada ciclo, então o vir-a-ser desenrolar-se-ia sem nenhum sentido último a atingir. Portanto, nada no Universo tenderia a um estado verdadeiramente final e acabado.

Caberia, nesse contexto, a ideia de causa formal? Também não! A forma momentânea de cada ente é fruto do jogo de forças que configura e reconfigura, a todo momento, as mais diversas formas da efetividade. Nesse sentido, a formas dos entes não expressariam uma estrutura ontológica essencial anterior ao combate das forças. Isto é, o que poderíamos entender como forma seria uma imposição do conflito de vontades de potência. Seria possível, entretanto, pensar as forças cósmicas como princípios materiais de todos os entes e acontecimentos deste cosmo? Ou seja, por constituírem todos os entes que surgem no devir, seriam elas a causa material desses entes? Decididamente, não podemos entender as forças em termos de princípios ontológicos materiais. As forças, que em eterna luta movimentariam o devir circular, não seriam eternas em-si-mesma. Tampouco, nenhuma delas seria "causa não causada". Todas elas, constantemente, engendrariam e seriam engendradas, pereceriam e fariam perecer. Além disso, se tomarmos o eterno ciclo da repetição do mesmo como premissa, fica inviável concebermos uma anterioridade material das forças em relação a qualquer ente. Ora, caso pudéssemos dizer que um ente qualquer é efeito de determinadas forças - porque é constituído por essas forças —, então também poderíamos afirmar que esse mesmo ente é a causa efetiva dessas mesmas forças que o compõe. Isso porque, no tempo circular do eterno retorno, as forças que compõem os entes são engendradas a partir das configurações dos entes que elas mesmas compõem. Por exemplo, as forças que constituem o corpo de um homem perecerão e retornarão a aparecer por conta de todas as configuraçôes cósmicas que existiram - inclusive 
o próprio corpo deste homem. Aqui, estamos longe da noção de causa material de Aristóteles, pois se pudéssemos compreender as forças nos termos de uma causa material, teríamos de entender essa causa material como efeito de seu próprio efeito, isto é, dos entes que elas mesmas constituem.

Seguindo o mesmo raciocínio que utilizamos para problematizar a dualidade causa e efeito, poderíamos afirmar que a dicotomia "determinação versus liberdade" também se dissolveria, uma vez que todo transcorrer necessário do vir-a-ser circular "passaria" pelas açôes de cada homem. ${ }^{25} \mathrm{Se}$, na cosmovisão do eterno retorno, cada homem é compreendido como parte integrante da totalidade do Universo cíclico - pois cada "um é necessário, é um pedaço de destino, pertence ao todo, está no todo" ${ }^{\text {26 }}$-, então as açôes de cada homem também "determinariam" as "causas" do eterno retorno de todas as forças que vieram a engendrar esses mesmos homens. Se, por um lado, a ação humana seria a "filha" das configurações das forças cósmicas, por outro lado, essa mesma ação seria a "mãe" das mesmas forças que vieram a possibilitá-la. Teríamos, consequentemente, uma necessidade circular sem início nem fim na qual seria impossível apontar qual desses polos é exclusivamente determinante ou qual deles é exclusivamente determinado. ${ }^{27}$ Em outras palavras, o jogo de forças e a ação de cada homem — que também é força - "determinar-se-iam" reciprocamente. ${ }^{28}$ Enfim, o ego de cada homem estaria emaranhado ao nó de "causas" do retorno de todas as coisas, tal como proclamam os animais de Zaratustra" : "Eu próprio estou entre as causas do eterno retorno". ${ }^{\circ}$

25 Jeane Champeaux, no artigo Fatalisme et volontarisme chez Nietzsche, afirma que, se entendermos bem o pensamento do trágico, a hipótese da vontade de potência e a doutrina do eterno retorno, poderíamos "compreender como Nietzsche finalmente pode ultrapassar a dicotomia do fatalismo e do voluntarismo" (Champeaux, 2000, p. I63). Nisso, estamos de acordo com a comentadora. Entretanto, não entendemos que a argumentação da autora, nesse artigo, tenha sido satisfatória.

26 Nietzsche, Os quatro grandes erros $\$ 8,2006$, p. 46.

27 Fornazari já havia apontado essa questão em: Fornazari, 2004, p. 51 e 52. Conferir também a posição de Nasser em: Nasser, 20I6, pp. 324-326.

28 Haar já havia assinalado essa noção de necessidade em Nietzsche quando ele afirma que "a lógica tradicional proíbe confundir a ordem da liberdade, a ordem do acaso e a ordem do destino [...] [Nietzsche, ao contrário,] faz surgir das velhas oposições uma nova ligação, uma nova necessidade" (Haar, 1993, p. 6I).

29 Acerca dessa relação entre a noção de ego fatum e a doutrina do eterno retorno do mesmo, conferir a posição de Löwith: "a existência [...] sem saída se projeta no fatum, como se seu ego particular pertencesse às condiçōes necessárias da organização sempre idêntica do mundo físico" (Löwith, I998, p. II7). Outro autor que vai numa direção parecida é Fink. Ver: Fink, 1988, p. II4. Seguindo a trilha percorrida por Löwith temos, no Brasil, Sandro Kobol Fornazari (cf. Fornazari, 2004, p. 50).

30 Assim falava Zaratustra, "O convalescente", $\$ 2$, KSA 4.276, tradução de PCs. 
Se pensarmos à luz desse argumento cosmológico, não cabe, por conseguinte, conceber as ações humanas como algo destacado do fluxo circular das forças, pois enquanto parte essencial deste, elas dependeriam, necessariamente, de todos os acontecimentos do mesmo fluxo circular. Assim, a ação humana viria sempre atrelada a um fado e vice-versa. Aqui, a velha oposição exclusiva entre liberdade versus determinação ficaria sem sentido. ${ }^{31}$ Isso porque, caso pensemos a partir da cosmologia do eterno retorno, o ser humano não poderia ser entendido, nem como um sujeito portador de livre-arbítrio (destacado do cosmo), nem como um autômato (impotente frente ao vir-a-ser), mas teria de ser compreendido como uma das configurações de forças atuantes e necessárias ao cosmo. ${ }^{32} \mathrm{Em}$ outras palavras, no contexto do eterno retorno, o cumprimento do fado passa, necessariamente, pelo homem, parte essencial do todo cósmico. Enfim, teríamos, portanto, um fatalismo circular sem início nem fim, no qual seria impossível apontar o que é exclusivamente determinante e o que é exclusivamente determinado.

\section{Referências}

Champeux, J. "Fatalisme et volontarisme chez Nietzsche". In: Balaude, J.-F.; Wotung, P. (Orgs.). Lectures de Nietzsche. Paris : Le livre de poche, 2000.

FInk, E. A Filosofia de Nietzsche. Lisboa: Presença, 1988.

ForNaZARI, S. K. Sobre o suposto autor da autobiografia de Nietzsche: reflexōes sobre Ecce Homo. São Paulo: Discurso; Ijuí: unijuí, 2004.

HaAr, M. Nietzsche et la métaphysique. Paris: Gallimard, 1993.

Itaparica, A. L. M. Verbete "Causalidade". In: gen. Dicionário Nietzsche. São Paulo: Loyola, 2016.

31 Aqui estamos, em parte, próximos da interpretação de Zuboff: "Nietzsche não acredita no que ele denomina determinismo nem [tampouco] em vontade livre". No entanto, estamos distantes de Zuboff quando - apesar de admitir que Nietzsche se opóe ao determinismo - assevera que a doutrina do eterno retorno mantém uma forma específica de determinismo. No nosso entender, não haveria sentido falar em determinismo ou liberdade, pois a doutrina do eterno retorno pretende, justamente, superar a dicotomia "determinismo x liberdade". Ver: (Zuboff, i980, p. 349).

32 Nesse ponto específico, estamos de acordo com Ivan Soll, Karl Löwith e Scarlett Marton. Conferir: a "vida humana é parte [...] das series de combinaçôes que constituem o ciclo cósmico" (Soll, I980, p. 334). A esse mesmo respeito, conferir também o comentário de Löwith: "o homem participa necessariamente desse jogo [...] porque a existência humana é um anel dos anéis do eterno retorno" (Löwith, I998, p. III). Conferir, ainda: "negando a oposição entre ego e fatum, acredita que o ser humano partilha o destino de todas as coisas. [...] o eterno retorno é parte constitutiva de um projeto que acaba com a primazia da subjetividade. Destronado, o homem deixa de ser um sujeito frente à realidade para tornar-se parte do mundo" (Marton, 200I, pp. II7-II8). 
Itaparica, A. L. M. "Livre-arbítrio". In: gen. Dicionário Nietzsche. São Paulo: Loyola, 2016.

Lalande, A. Vocabulário técnico e crítico da filosofia. São Paulo: Martins Fontes, I999.

Löwiтh, K. Nietsche, philosophie de l'éternel retour du même. Trad. Anne-Sophie Astrup. Paris: Hachette littératures, 1998.

Marton, S. "O Eterno Retorno do Mesmo: Tese Cosmológica ou Imperativo Ético?”. In: Marton, S. Extravagâncias: ensaios sobre a Filosofia de Nietzsche. São Paulo: Discurso editorial/Editora Unijuí, 200 .

Marton, S. "Por uma filosofia dionisíaca". In: Marton, S. Nietzsche seus leitores e suas leituras. São Paulo: Barcarola, 2010.

Melo Neto, J. E. T. Verbete "Fatalismo". In: gen. Dicionário Nietzsche. São Paulo: Loyola, 2016.

Nasser, E. Verbete "Necessidade". In: gen. Dicionário Nietzsche. São Paulo: Loyola, 2016.

Nietzsche, F. Sämtliche Werke. Kritische Studienausgabe (кsa). Organizada por Giorgio Colli e Mazzimo Montinari. Berlim: Walter de Gruyter \& Co., I999, I5 v.

Nietzsche, F. "Fado e História". In: Nietzsche, F. Genealogia da Moral. Trad. Paulo César de Sousa. São Paulo: Companhia das Letras, 2005.

Nietzsche, F. Humano, demasiado humano II. Trad. Paulo César de Sousa. São Paulo: Companhia das Letras, 2008.

Nietzsche, F. Crepúsculo dos idolos. Trad. Paulo César de Sousa. São Paulo: Companhia das Letras, 2006.

Nietzsche, F. Assim falou Zaratustra. Trad. Paulo César de Sousa. São Paulo: Companhia das Letras, 20II.

Platão. "Fedão". In: Platão. Diálogos. Protágoras, Górgias e Fedão. trad. Carlos Alberto Nunes. 2. ed. Belém: EDUfPa, 2002.

SolL, I. "Reflexions on recurrence: a re-examination of Nietzsche's doctrine, die Ewige Wiederkehr des Gleichen". In: Solomon, R. C. (Orgs.). Nietzssche, a collection of critical essays. Notre Dame: University of Notre Dame Press, 1980.

Zuboff, A. "Nietzsche and eternal recurrence". In: Solomon, R. C. (Orgs.). Nietzsche, a collection of critical essays. Notre Dame: University of Notre Dame Press, 1980. 